\title{
Motivation of Voluntary Activity and Personal World Assumptions of the Youth
}

\author{
Marina M. Solobutina*1, Margarita Nesterova ${ }^{2}$ \\ ${ }^{1}$ Kazan Federal University, Institute of Psychology and Education, Kazan, Russia, ${ }^{2}$ Daugavpils University, Institute of \\ Humanities and Social Sciences, Daugavpils, Latvia, \\ Email: solomarina29@gmail.com, Tel.+79033424506, margarita.nesterova@du.lv, Tel.+37126443082
}

Received: 21st October 2017 Accepted: 16th November 2017, Published: 31st December 2017

\begin{abstract}
The paper presents results of research of volunteer activity motivation for young people in interrelation with world assumptions of a person. As a hypothesis of the study, it was suggested that the motivation for volunteer activity in the adolescence period is grounded on certain world assumptions and personal values. The study used the following methods: the World assumptions scale (R.Janoff-Bulman); and the Purpose-in-Life Test (J.Crumbaugh \& L.Maholic). A semantic differential has been developed to study the motivation of volunteer activity. With the help of factor analysis, two leading motivations of volunteer activity were revealed: motives of personal growth and idealistic motives. The study was a comparative analysis of the studied indicators in a group of volunteers and in a group of young people not engaged in volunteer activity. It was determined that the motivation of volunteers in teens is based more on external factors (positive attitude of others, social significance, social contacts) and is not determined by deep world assumptions of the individual. The value of the "I" depends more on the idealistic beliefs and the personal orientation toward their support than on the meaningfulness and fruitfulness of one's own life.
\end{abstract}

Keywords: Motivation, Volunteer Activity Motivation, World Assumptions, Purpose-in-Life Orientations, Volunteers.

\section{Introduction}

The relevance of the research lies in the fact that volunteer activity has recently acquired a special social significance and popularity which were in demand in carrying out a number of mass international events in many countries, and it was an indicator of public consciousness and social improvement of the state at the international level. The increasing need for a large number of volunteers reveals the need for their involvement and selection, what brings to the fore the problem of motivating volunteer activity [6].

Volunteering increasingly becomes the object of scientific research in the field of psychology and social sciences, and is considered as gratuitous activity aimed at offering benefits to people and society [30]. A greater number of young people are attracted to largescale events, in which the psychological stability of volunteers, their motivations that lead to this activity is important [10].

Volunteer activity is analyzed from different positions, beginning with receiving by the participants of positive psychological experiences from carrying out activities, and up to the prerequisites of moral upbringing. It is often viewed as pro-social and altruistic behavior provided by motives of duty, care and sympathy [3]. The review of scientific publications devoted to the problem of motivating volunteer activity made it possible to determine the main aspects of its study [5]. Three directions can be distinguished in studying the motivation of volunteer activity. The first is devoted to the structural content characteristics of this activity, the second to the psychological characteristics of volunteers, and the third focuses on organizational psychology.

Structure of voluntary activity was investigated through the structure of activity as a whole and its value-semantic aspect $[2 ; 12 ; 15 ; 18]$. In the general psychological theory of activity by A.N. Leontiev, question about the "semantics" of activity is central, and the category of activity motivation is central and closely related to the concept of meaning [19]. D.A. Leontiev considers the personal senses of man as the basis of motivational processes [20;21].

Researchers of volunteer activity motivation quite often consider it in the sense of altruistic and pro-social behavior [16]. Altruism emerges from personal motives, without pressure from outside, and is based on the moral principles of society.

The nature and content of motivation directly depends on the direction of volunteering activity. It is possible to identify various areas of volunteer activity: assistance to needy and vulnerable social groups [4], work in hospitals [26;27; 29], palliative care [7], prevention of deviant behavior, work on the improvement of territories, preservation of cultural heritage, environmental activities, organization of mass leisure and sports events, etc. [24].

In studies of the second direction, it is proved that the individual psychological characteristics of the volunteer determine the nature of the implementation of volunteer activity $[14 ; 16]$. A. Maslow distinguishes between two types of motivation: the usual motivation of people who have not reached self-actualization, and the motivation of people living "beyond" selfactualization, on the level of Being [22]. For its characterization, he introduced the concepts of "Bvalues" and "metamotivation". V. Frankl considered altruism as an opportunity for a person to achieve the meaningfulness of their life [11]. In many studies of volunteer work, the leading motive is the process of the activity itself aimed at helping others and based on responsibility and religious beliefs. It is important to 
consider the issues of meaningfulness of life and responsibility in the context of forecasting life events and the consequences of the activity [1], what will allow us to more deeply explore the internal motivation of actively helping others. A number of studies are known, in which the motivation of volunteer activity is considered in the context of the life course of an individual and the age-related stage of development $[25 ; 28]$.

The third group of studies is devoted to the study of volunteer activity in organizational psychology and is related to the selection of applicants for volunteer work and the phenomenon of continuity and involvement in the organization assisting the mission $[13 ; 23]$.

In this study, an attempt was made to supplement the main provisions of the motivation of voluntary activity by the example of volunteer movements, based on the analysis of knowledge in this area. The practical importance of the study is determined by the ability to use the data obtained for the development of the volunteer movement, as well as an understanding of the personal characteristics of people engaged in volunteer activity.

\section{Methods}

The purpose of our research is to study the characteristics of the motivational sphere of people engaged in volunteer activity, in conjunction with world assumptions and Purpose-in-Life orientations. As a hypothesis of the study, it was suggested that the motivation for volunteer activity in the adolescence period is based on certain world assumptions and personal values.

The study used the following methods as personality orientations, namely, World assumptions scale (JanoffBulman [17], adaptated by O. Kravtsova); Purpose-inLife Test (James Crumbaugh \& Leonard Maholic [8; 9], adapted by D.A. Leontiev). A semantic differential has been developed to study the motivation of volunteer activity. We also used methods of empirical data statistical processing: analysis of differences ( $t$ test), factor analysis, and Pearson correlation analysis.

The total sample size was 100 people, of which 50 young men and women were volunteers in sports championships. The remaining 50 people, not engaged in volunteer activity, made up a control group. The average age of subjects: $20-25$ years.

\section{Results and Discussion}

Learning the world assumptions of volunteers

As to samples of volunteers and test subjects not engaged in volunteer activity, there are significant differences in terms of world assumptions only on the scale of "Kindness of people" (for $p=0.05$ ). Volunteers have a world assumption (basic belief) in goodwill of people. They believe that most people in the world are disinterested, friendly, affable, tend to make a good impression on others, show their good qualities to others. Volunteers are convinced of the strength of a positive attitude towards people, the power of justice in spite of hostility and bitterness (Table 1).

Table 1. Analysis of the Mean Values for Indicators of World Assumptions in the Compared Groups

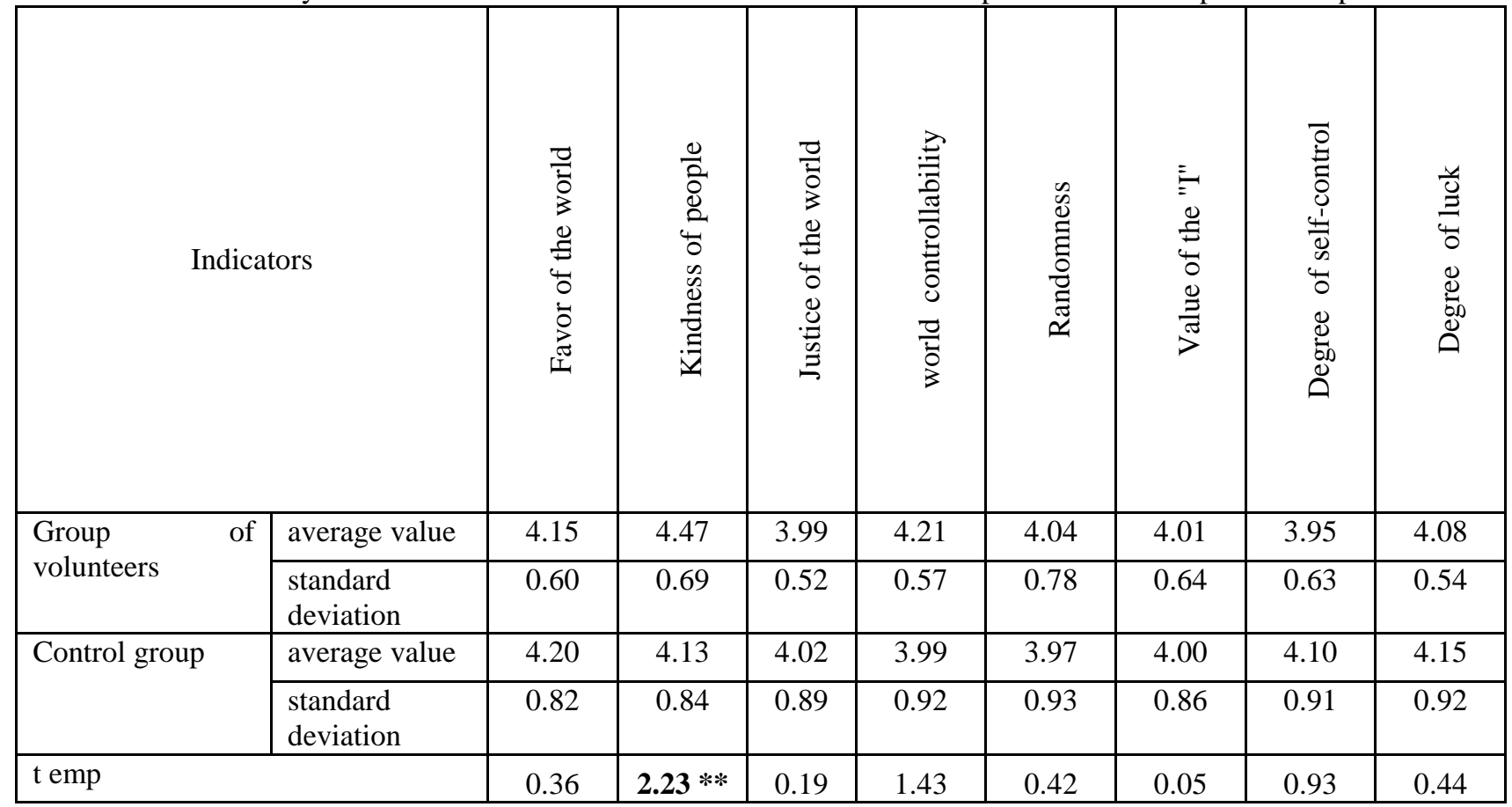

With respect to other world assumptions, the values obtained in the compared groups are not statistically different. Both groups of subjects are characterized by a belief in indulgence, a supportive attitude of people in society. They are convinced that they are able to control the situations that occur in their lives. According to the results of diagnostics, the testimony is characterized by a rather high level of value of the "I", 
a sense of its importance in relations with other people. It can be assumed that this is due to approximately the same age category in the group of volunteers and in the control group, which implies that volunteer activity has not significantly affected their world assumptions, or world assumptions are not a decisive factor in motivating volunteer activity. The only significant difference in the world assumptions between volunteers and the control group is that volunteers are convinced of the kindness of people, they believe that there are many good people in the world who are capable of good deeds.

\section{The Study of the Purpose-in-Life Orientations of Volunteers}

The purpose-in-life test (PIL) is developed on the basis of the theory of the need for meaning and logotherapy of V. Frankl "Purpose in life", which the authors define as rueful feelings of an individual on the ontological significance of his/her life.

Table 2. Analysis of the average values for indicators of Purpose-in-Life orientations in the compared groups

\begin{tabular}{|c|c|c|c|c|c|c|c|}
\hline \multicolumn{2}{|c|}{ Indicators } & $\begin{array}{l}\stackrel{\oplus}{\Xi} \\
. \Xi \\
\cong\end{array}$ & 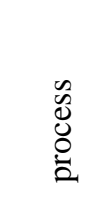 & $\begin{array}{l}\stackrel{0}{\Xi} \\
\stackrel{0}{0} \\
\stackrel{=}{=}\end{array}$ & $\begin{array}{l}\overline{0} \\
\stackrel{\Xi}{0} \\
0 \\
\delta \\
= \\
=\end{array}$ & 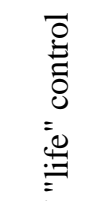 & 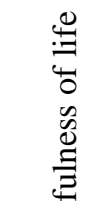 \\
\hline \multirow{2}{*}{$\begin{array}{c}\text { Group of } \\
\text { volunteers }\end{array}$} & Average value & 30.50 & 31.78 & 26.04 & 21.12 & 30.68 & 103.92 \\
\hline & Standard deviation & 5.76 & 5.82 & 4.18 & 4.07 & 5.89 & 16.83 \\
\hline \multirow{2}{*}{ Control group } & Average value & 30.96 & 30.22 & 25.48 & 20.86 & 31.64 & 102.94 \\
\hline & Standard deviation & 6.21 & 6.20 & 5.53 & 4.33 & 5.37 & 17.82 \\
\hline \multicolumn{2}{|l|}{ t emp } & 0.38 & 1.3 & 0.57 & 0.31 & 0.85 & 0.28 \\
\hline
\end{tabular}

There were no significant differences in the indices of Purpose-in-Life orientations in the compared groups of subjects (Table 2). From this, it can be concluded that young people share similar vital meanings, regardless of volunteer activity. For all young people in the general sample, none of the scales is prominent and significant. We believe that this is quite understandable by the age category of the subjects. The youthful age is characterized by the desire for self-determination in life, setting goals, opportunities and personal resources in achieving them. Volunteers and young people in the control group are characterized by self-reflection, which is manifested in assessing the past stage of life, understanding its productivity and the need to enter adulthood and a sense of responsibility for their decisions. The prevailing tendency in studying Purpose-in-Life orientations of subjects is the uncertainty and comprehension of their path in life.

\section{Development of a Semantic Differential for the Study of Volunteer Activity Motives}

Within the framework of this study, a semantic differential has been developed, for which one hundred statements were selected that characterize one or another motive of volunteer activity represented in well-known theories. The results of the semantic differential were subjected to factor analysis, during which all statements were divided into two groups: "Motives for personal growth", which includes 22 statements, and "Idealistic motives", which includes 17 statements. The remaining statements were deleted due to low significance indicators.

In the group of persons not engaged in volunteer activity, the values of "Motives for personal growth" prevail over the values of the tested group of volunteers $(\mathrm{t}=4,42 * * * *)$. This result indicates a more pronounced desire for self-realization, selfimprovement, and development of self-awareness among people who do not engage in volunteer activity. Comparative analysis of "Idealistic motives" in the compared groups indicates the identical nature of the data representation $(t=1.59)$ revealing the desire to contribute to changes in society, to be socially useful, to help those in need, to be responsible for good, to fight a certain problem, to improve the well-being of another personality, as well as moral duty and empathy. Idealistic motives are equally important for young people of both groups.

Thus, the hypothesis that there are specific features of the motivational sphere of people engaged in volunteer activity is confirmed, since the differences in the first factor "Motives for personal growth" were revealed.

These characteristics are natural for the age group of 20 - 25 years, and are a reflection of the major innovations of youth. For this age, awareness of one's own individuality, readiness for self-determination, gradual ingrowing into various spheres of life, the search for solutions to basic worldview problems are characteristic. Nevertheless, despite the lack of statistical confirmation, it is worth noting that for volunteers the average values on idealistic reasons are 
slightly higher than those of the second group. This observation can be seen as desire to be useful to society and help others which is more typical for volunteers.

Identification of the Nature and Extent of the Relationship between the Motives of Volunteer Activity, the World Assumptions of an Individual and the Purpose-in-Life Orientations

In the control group, the correlation analysis did not reveal any significant relationship between the indices of the world assumptions and the sense of life. In the group of volunteers, these indicators were closely interrelated (Table 2). The identifying beliefs for volunteers are belief in the favor of the world, belief in one's own value and ability to self-control, which activate the Purpose-in-Life orientations of a person connected with the meaningfulness of life, goal-setting, a sense of effectiveness and richness of life, and with the ability to control oneself and one's life.

The motives of volunteer activity are not related to any of the questionnaire indicators on world assumptions and Purpose-in-Life orientations of the control group, while in the group of volunteers the motive of personal growth is interlinked with the conviction of the kindness of people, and idealistic motives are interrelated with a number of indicators of Purpose-inLife orientations related with a sense of meaningfulness of life, the fruitfulness of the past part of life, as well as indicators of world assumptions about the controllability and justice of life.

Table 3. Matrix of Correlations between the Studied Indicators in the Group of Volunteers

\begin{tabular}{|c|c|c|c|c|c|c|c|}
\hline Indicators & 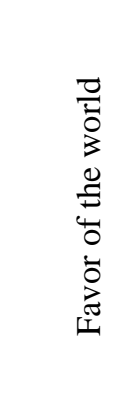 & 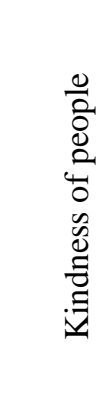 & 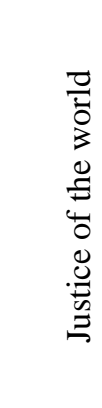 & 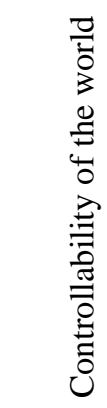 & 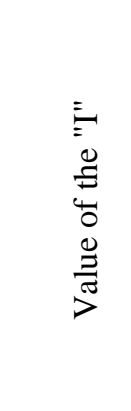 & 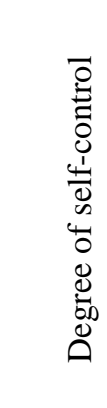 & 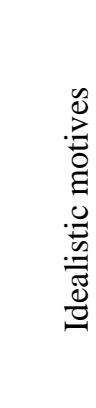 \\
\hline Goals in life & $\mathbf{0 . 4 7} * *$ & & & & $0.40 *$ & & \\
\hline Process of life & $0.51 * *$ & & & & & 0.34 & \\
\hline Result of life & $0.51 * *$ & & & & 0.36 & $0.38 *$ & 0.36 \\
\hline Locus of control I & $0.41 *$ & & & & 0.37 & 0.3 & 0.36 \\
\hline Locus of life control & 0.33 & & & & $0.53 * *$ & & $0.38 *$ \\
\hline Meaningfulness of life & $0.48 * *$ & & & & $0.41 *$ & 0.32 & 0.32 \\
\hline Motives for personal growth & & 0.47 & & & & & \\
\hline Idealistic motives & & & -0.32 & 0.29 & & & \\
\hline
\end{tabular}

\section{Conclusion}

1. It was revealed that in contrast to the subjects of the control group, the volunteers have prevailing belief in the justice of the world, the strength of kindness and the responsiveness of people. It is characteristic of them to believe in a special attitude on the part of society towards their activities, which consists in gratitude and a positive assessment of their personal qualities. Also their belief is dominated that the development of society, the situation in society, and in the world in general, depend on the personal contribution of specific people through their activities, the central motive of which is to improve the structure of society and human values.

2. Certainly, the Purpose-in-Life orientations of volunteers are blurred, and unformed life program is behind the facade of volunteer activity. Inclusion in life and self-relationship are determined by the social importance of volunteering and depend on the approval of the surrounding people that they devote themselves to unpaid work.
3. To study the motivational sphere of volunteers, a semantic differential was developed, as a result of which two main motives of volunteer activity were identified: motives of personal growth and idealistic motives.

4. The results of the correlation analysis led to the conclusion that perceptions of personal growth and the formation of personality of volunteers are determined by external factors, such as the favor of the world, public recognition and the positive attitude of surrounding people. The value of the "I" depends more on the idealistic beliefs and the person's orientation toward their maintenance than on the meaningfulness and fruitfulness of one's own life.

\section{Acknowledgements}

The work is carried out according to the Russian Government Program of Competitive Growth of Kazan Federal University. 


\section{References}

1. Akhmetzyanova, A.I. (2016). The theoretical analysis of the phenomenon of anticipation in psychology. International Journal of Environmental and Science Education, 11(7), 1559-1570.

2. Azarova, E.S., Yanitskiy, M.S. (2008). Psychological determinants of volunteer's activity. Journal of Tomsk State University, 306, 120-125.

3. Batson, C.D. (1998). Altruizm and prosocial behavior. The Handbook of Social Psychology, $4^{\text {th }}$ edn. New York: McGraw-Hil, 262-316.

4. Bidee, J., Vantilborgh, T., Pepermans, R., Willems, J., Jegers, M., \& Hofmans, J. (2017). Daily motivation of volunteers in healthcare organizations: Relating team inclusion and intrinsic motivation using self-determination theory. European Journal of Work and Organizational Psychology, 26(3), 325-336. doi:10.1080/1359432X.2016.1277206

5. Clary, E. G., \& Snyder, M. (1999). The motivations to volunteer: Theoretical and practical considerations. Current Directions in Psychological Science, 8(5), 156-159.

6. Clary, E. G., Ridge, R. D., Stukas, A. A., Snyder, M., Copeland, J., Haugen, J., \& Miene, P. (1998). Understanding and assessing the motivations of volunteers: A functional approach. Journal of Personality and Social Psychology, 74(6), 1516-1530.

$7 . \quad$ Claxton-Oldfield, S., Jefferies, J., Fawcett, C., Wasylkiw, L., \& Claxton-Oldfield, J. (2004). Palliative care volunteers: Why do they do it? Journal of Palliative Care, 20(2), 78-84.

8. Crumbaugh, J. C. (1968). Cross-validation of purpose-in-life test based on frankl's concepts. Journal of Individual Psychology, 24(1), 74-81.

9. Crumbaugh, J. C., \& Maholick, L. T. (1964). An experimental study in existentialism: The psychometric approach to Frankl's concept of noogenic neurosis. Journal of Clinical Psychology, 20(2), 200207.

10. Finkelstein, M. A., Penner, L. A., \& Brannick, M. T. (2005). Motive, role identity, and prosocial personality as predictors of volunteer activity. Social Behavior and Personality, 33(4), 403-418.

11. Frankl, V. E. (1982). The suffering person in search of meaning. Osterreichische Krankenpflegezeitschrift, 35(1), 10-12.

12. Haivas, S., Hofmans, J., \& Pepermans, R. (2013). Volunteer engagement and intention to quit from a self-determination theory perspective. Journal of Applied Social Psychology, 43(9), 1869-1880. doi:10.1111/jasp.12149

13. Haski-Leventhal, D., \& Bargal, D. (2008).

The volunteer stages and transitions model: Organizational socialization of volunteers. Human Relations, 61(1), 67-102. doi:10.1177/0018726707085946

14. Heckhausen, J., \& Heckhausen, H. (2008). Motivation and action. Motivation and action. doi:10.1017/CBO9780511499821

15. Houle, B.J., Sagarin, B.J., Kaplan, M.F. (2005). A Functional Approach to Volunteerism: Do
Volunteer Motives Predict Task Preference? Basic and Applies Social Psychology, 27(4), 337-344.

16. Ilin, E.P. (2011). Motivation and motives. $\mathrm{SPb}$ : Piter.

17. Janoff-Bulman, R. (1989). Assumptive worlds and the stress of traumatic events: Applications of the schema construct. Social cognition, Special Issue: Social Cognition and Stress, 7(2), 113-137.

18. Kosova, U.P. (2012). Motivation of volunteers' activities. Journal Collection of Scientific Works of KRASEC, Section "The Humanities”, 2(20), 123-127.

19. Leont'ev, A.N. (1978). Activity: consciousness and personality. Englewood Cliffs: Prentice-Hall.

20. Leontiev, D.A. (2012). Personal meaning as the basis of motivational processes. Motivation, consciousness and self-regulation,65-78.

21. Leontiev, D.A. (2016). Personal meaning: A challenge for psychology. Positive psychology in search for meaning.

22. Maslow, A.H. (1987). Motivation and personality. New York: Harper and Row.

23. Millette, V., \& Gagné, M. (2008). Designing volunteers' tasks to maximize motivation, satisfaction and performance: The impact of job characteristics on volunteer engagement. Motivation and Emotion, 32(1), 11-22. doi:10.1007/s11031-007-9079-4

24. Monga, M. (2006). Measuring Motivation to Volunteer for Special Events. Event Management, 10(1), 47-61.

25. Omoto, A. M., Snyder, M., \& Martino, S. C. (2000). Volunteerism and the life course: Investigating age-related agendas for action. Basic and Applied Social Psychology, 22(3), 181-197.

26. Planalp, S., \& Trost, M. (2009). Motivations of hospice volunteers. American Journal of Hospice and Palliative Medicine, 26(3), 188-192. doi:10.1177/1049909108330030

27. Scott, R., Butler, D., \& Wilson, S. (2017). Volunteering in bereavement: Motivations and meaning. Bereavement Care, 36(2), 55-57. doi:10.1080/02682621.2017.1305052

28. Thoits, P. A., \& Hewitt, L. N. (2001). Volunteer work and well-being. Journal of Health and Social Behavior, 42(2), 115-131.

29. Wach, D., Hentschel, L., Rosenkranz, B., \& Rudolf, M. (2017). Motivational and health impairment processes among german hospice volunteers: Predictors of retention intention and psychological health. Zeitschrift Fur Arbeits - Und Organisations psychologie, 61(3), 137-151. doi:10.1026/09324089/a000243

30. Wilson, J. (2000). Volunteering. Annual Review of Sociology,26(1), 215-240. 